\title{
A Multilevel Analysis of Persistence of Students Taking a Pre-Engineering Curriculum in High School
}

\author{
Brandon Sorge and Charles Feldhaus \\ Indiana University Purdue University Indianapolis \\ Indianapolis, IN, USA
}

\begin{abstract}
Using data from the 2010 Indiana, USA public high school graduating class $(\mathrm{N}=55612)$, this project employed a multi-level analysis to determine, what if any differences occurred in majoring in science, technology, engineering, and math and freshman to sophomore year persistence, between students attending a school that offers Project Lead the Way and students that don't, while controlling for being a PLTW student. Results imply that PLTW had a statistically significant impact on the students participating in the program excluding students who were eligible for free and reduced lunch. However, this impact does not appear to carry over to the rest of the student body that does not participate in PLTW.
\end{abstract}

Keywords: Project Lead the Way; student persistence; pre-engineering curricula; hierarchical linear modeling.

\section{Introduction}

For many years the debate about the importance of science, technology, engineering and math within the P-12, post-secondary, and United States workforce has been controversial. One thing is certain, since the publication of the seminal reports Rising Above the Gathering Storm by the National Academy of Science (2006) and STEM Education: Preparing for Jobs of the Future by the US Congress Joint Committee (2012) claimed that there was a shortage of science, technology, engineering, and mathematics (STEM) workers, and that the shortage would last well into the future endangering US national security, STEM has been at the forefront of a national discussion.

Often STEM education is promoted for the potential to improve student ability and to act as a catalyst for students entering science and engineering fields (Ring, Dare, Crotty, \& Roehrig, 2017). Although the definition of STEM and what STEM education entails are still under discussion, it is more or less agreed that it should integrate some or all the subjects of science, technology, 
engineering, and mathematics (Moore \& Smith, 2014). Moreover, besides the integration of multiple subjects, STEM education also features instructional practices that focus on inquiry-based, hands-on, and problem- solving activities (Thibaut, Knipprath, Dehaene, \& Depaepe, 2018). Some research suggests that the essence of STEM education lies in its potential to engage students in authentic situations that utilize their existing knowledge in multiple disciplines to solve problems (Wang, Moore, Roehrig, \& Park, 2011).

Recent large-scale government-funded STEM reform projects in the USA produced the Next Generation Science Standards (NGSS), which established Grade 1-12 standards to provide a globally competitive STEM education and called for innovation and creativity in curriculum (Hoeg \& Bencze, 2017). In addition, there have been a number of policy initiatives at the state and federal level to integrate rigorous, hands-on, project-based, pre-engineering, science, and computer science curricula to help prepare the future STEM workforce. One of these initiatives is Project Lead the Way.

\section{Project Lead the Way}

According to the website (PLTW.org) Project Lead the Way (PLTW) provides rigorous, hands-on, project-based pre-engineering, science and computer science curriculum to 11,500 P-12 schools and millions of students in all 50 states, D.C., and U.S. Territories (Project Lead the Way, 2019). Nearly 70,000 P-12 teachers have received PLTW training, and initial studies have shown that the PLTW curriculum has had success in increasing student performance and interest in STEM (Bottoms \& Anthony, 2005; Laanan, Schenk, Starobin, Chapman, \& Zhang, 2009; Pike \& Robbins, 2014; Schenk et al., 2009; Van Overschelde, 2013). The PLTW Pathway to Engineering curriculum is a four-year high school sequence of courses that includes both foundation courses and elective courses. The PLTW Biomedical Science curriculum is a four-year high school sequence focused on the foundations of biomedical sciences.

The state of Indiana, USA, was an early adopter of PLTW. Beginning in 2005, Indiana's Department of Education and Department of Workforce Development implemented a funding policy to support implementation of PLTW in the state. This funding policy allocated money to schools to fund equipment, labs and software for PLTW programs as well as per student funding for each PLTW course completed. Funding was the same no matter school size, location, or financial status. The policy showed success in getting schools to adopt and, by 2010, approximately two-thirds of Indiana high schools offered PLTW courses, making Indiana the largest implementer of PLTW programs in the country.

\section{Research Methods, Design, and Data Collection}

Institutional factors often interact with program level factors to create observed outcomes. However, often research does not provide specificity. It also doesn't take into account the interplay between the nested structure of school systems and how these different levels interact. For example, Indiana's education system is under local control. A local school district governs multiple schools in grades K-12. These schools, in turn, have multiple students. Schools within the same district have different leadership, student demographics, and locations, but they 
still are governed by the same district rules and leadership. Students within different schools often have different experiences because of school characteristics and leadership but will have similar experiences based upon being in the same district. Students are nested within schools, which are nested within districts, with each sitting on a level higher than the other, and each level interacting with the other.

PLTW in Indiana provides an excellent opportunity to research and investigate these interactions at multiple levels. As shown in Figure 1, for purposes of this research, there are two groups of students, those who have taken a PLTW course and those who have not. Each of these groups has outcomes related to building the STEM workforce of having students major in STEM and then persisting from their freshman to sophomore year of college. While getting more students to major in STEM is an important first step in increasing the pipeline, a significant percentage of students majoring in STEM fields drop out of school before the start of their sophomore year or switch to a non-STEM major (Chen, Johri, \& Rangwala, 2018), making persistence an important attribute to understand.

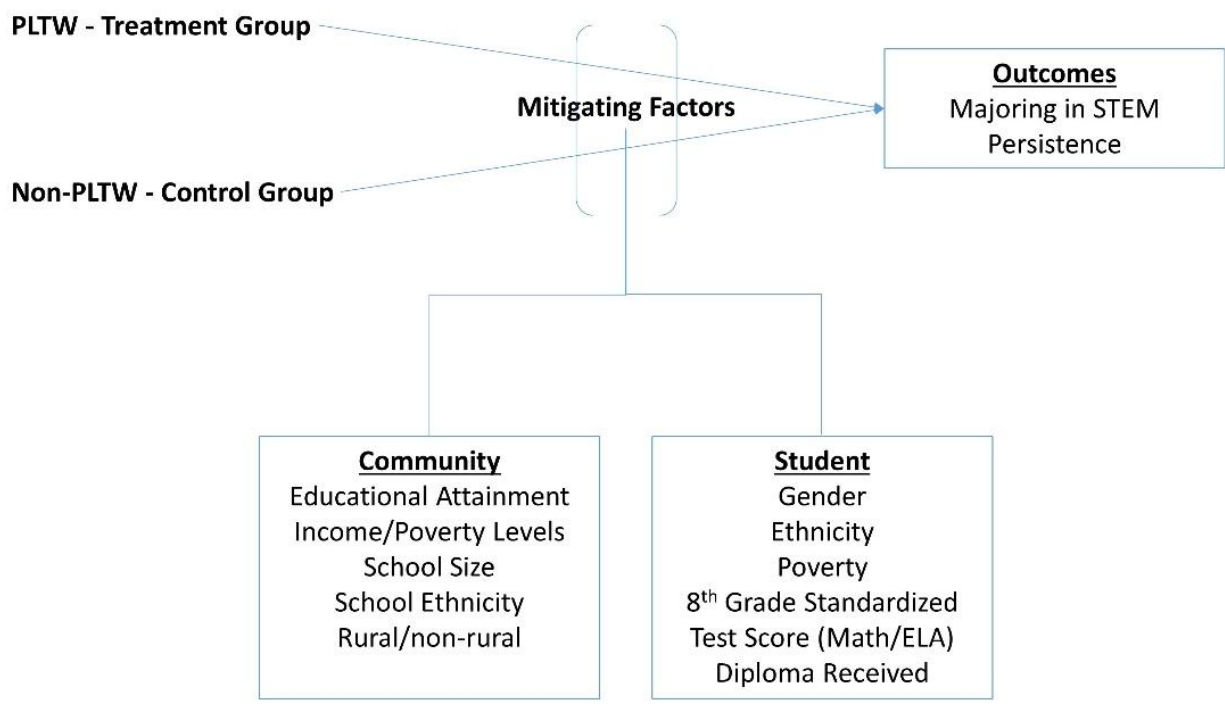

Figure 1: Model of research

Figure 1 also lists mitigating factors that impact students from each of these groups and the likelihood they will major in STEM and/or persist. The research done by McREL (2010), focused on education as a whole and not on STEM. Do these same or similar factors play a role in majoring in STEM or persistence? Utilizing these factors in a three level nested model-using district/community, school, and student level factors (see Figure 2) will provide new insight on outcomes relevant to STEM. Understanding the roles these factors play in policy implementation can help policy makers craft better policies, which in turn create institutional factors needed for program success. This is especially important in how these factors affect students majoring in a STEM field as well as their persistence from their freshman to sophomore year in post-secondary education when so many students drop out in Indiana and across the country. 
Level 3 - District/Community Level Data

- Rural or non-rural

- Percent of population with H.S. degree

- Percent of population with a bachelors degree

- Per capita income

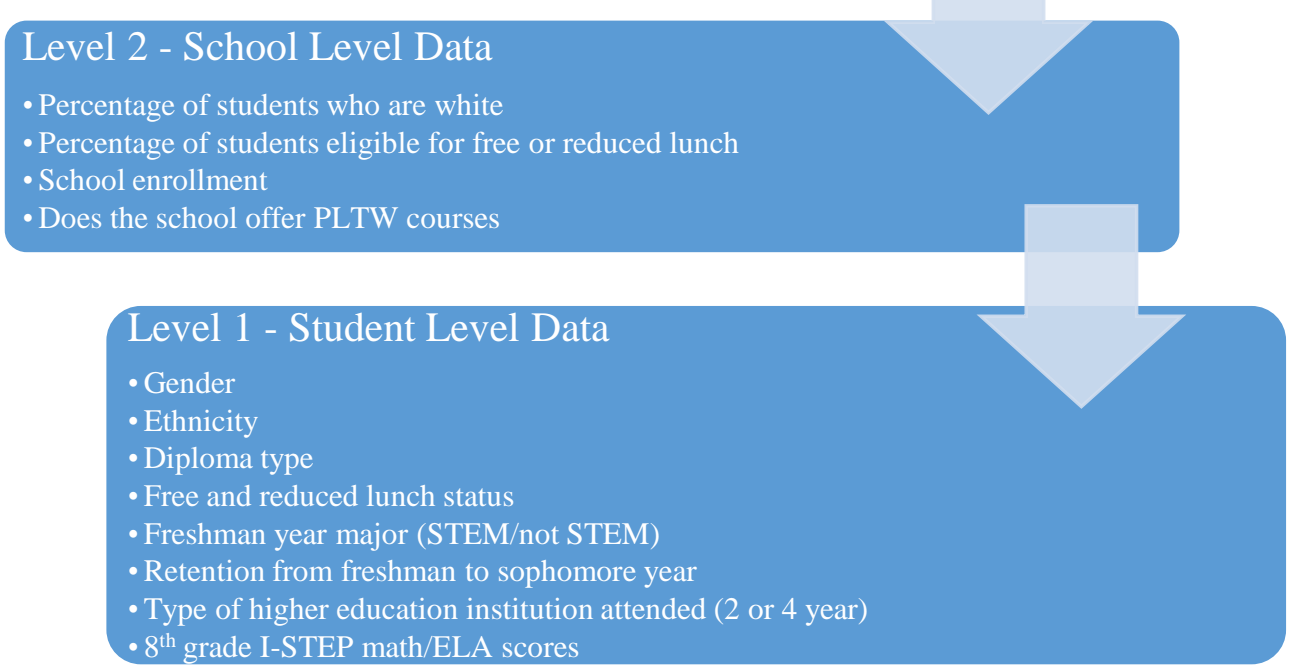

Figure 1: Nested levels of data

When looking at just the outcomes section of the model for research, see Figure 3 , the following research questions were formulated related to the outcomes of a student having their post-secondary major be in STEM and for persisting from their freshman to sophomore year of college:

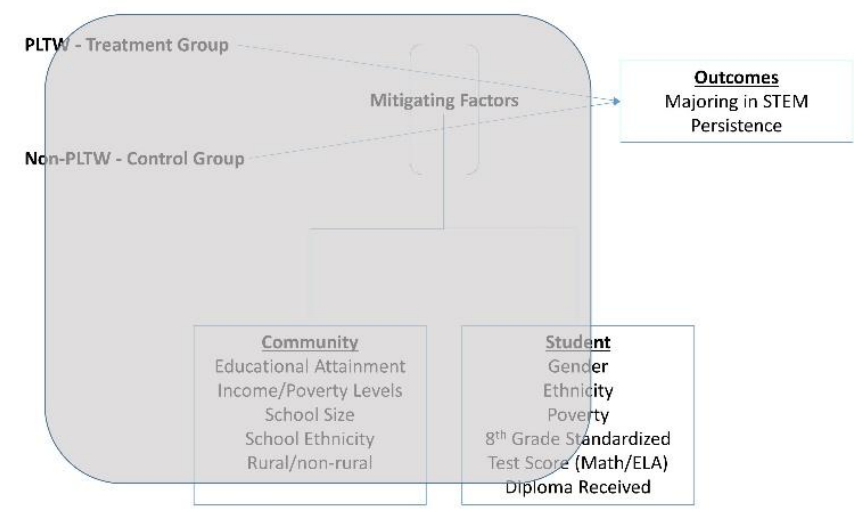

Figure 2: Outcomes

Two research questions were developed and are listed below followed by hypothesis 1 .

1. Does attending a school that offers PLTW increase the likelihood of students majoring in a post-secondary STEM program? 
2. Does attending a school that offers PLTW increase the likelihood that a student will persist from their freshman to sophomore year of college?

Hypothesis 1

$\mathbf{H}_{\mathbf{a}}$ : Attending a school that offers PLTW will increase the likelihood of students majoring in a post-secondary STEM program. This odds ratio will be greater if they have taken PLTW courses.

$\mathbf{H}_{\mathbf{0}}$ : Attending a school that offers PLTW will not increase the likelihood of students majoring in a post-secondary STEM program. This odds ratio will be greater if they have taken PLTW courses.

When controlling for students who took a PLTW course, attending a school that offers PLTW did not increase the likelihood of students majoring in STEM. We therefore cannot reject the null hypothesis. For this analysis, the dependent variable was if a student majored in STEM. This was a dichotomous variable coded as 0 (anyone who did not have a major in a STEM field during their first semester of higher education) and 1 (their major the first semester of higher education was in a STEM field). Three levels of data were used, where level 1 were student level data $(\mathrm{N}=55612)$, level 2 were school data $(\mathrm{N}=346)$, and level 3 were district/community level data $(\mathrm{N}=289)$. Table 4.9 provides basic information about the PLTW schools and the non-PLTW schools.

Table 1: Basic descriptive statistics of PLTW schools and non-PLTW schools

\begin{tabular}{lll}
\hline Descriptive & PLTW Schools & Non-PLTW Schools \\
\hline $\begin{array}{l}\text { Number of Schools } \\
\text { Percentage of Schools that are }\end{array}$ & 233 & 115 \\
rural & 42.9 & 43.5 \\
Maximum Enrollment & 3632 & \\
Minimum Enrollment & 171 & 4389 \\
Average Enrollment & 1035 & 53 \\
\hline
\end{tabular}

An initial unconditional analysis was run to determine if a three level model was appropriate. Because of the dichotomous outcome variable, use of a Bernoulli HLM3 analysis is appropriate for all analyses using the variable of STEM Major as the outcome variable (Raudenbush et al., 2011). The p-value for this unconditional model was $\mathrm{p}<.001$ indicating that the three level model was appropriate (Hox, Moerbeek, \& Van de Schoot, 2017). A model was then run including the dichotomous variable PLTWSCHL [school offers PTLW (1) or a school does not offer PLTW (0)]. The equation of this model is $\eta_{i j k}=\gamma_{000}+$ $r_{010}{ }^{*}$ ISPLTWSC $j k+r_{0 j k}+u_{00 k}$. The results of this model showed that students attending a PTLW school were more likely to major in STEM than students at a non PLTW School $(\mathrm{p}<.001, \mathrm{OR}=1.28)$. Further investigation was done to determine if PLTW students solely accounted for this difference. To determine this, another model was run to include and control for PLTW students. The results of this model, $\eta_{i j k}=\gamma_{000}+\gamma_{010}{ }^{*} I_{S P L T W S C} j k+\gamma_{100}{ }^{*} I S P L T W_{i j k}+r_{0 j k}+u_{00 k}$, were that PLTW students were more likely to major in STEM than non-PLTW 
students $(\mathrm{p}<.001, \mathrm{OR}=4.66)$ and attending a PLTW school was not significant $(\mathrm{p}=.672)$.

New models were created to further investigate the differences in majoring in STEM. Models were setup to compare PLTW students $(\mathrm{N}=4032)$ to non-PLTW students $(\mathrm{N}=37774)$ at their school, PLTW students to students at non-PLTW schools $(\mathrm{N}=13806)$ and non-PLTW students at PLTW schools to students at nonPLTW schools. Table 4.10 shows basic information about each of these groups of students.

Table 2: Basic descriptive statistics of student groups

\begin{tabular}{lccc}
\hline \multicolumn{1}{c}{ Descriptive } & PLTW Students & $\begin{array}{c}\text { Non-PLTW Students } \\
\text { at PLTW Schools }\end{array}$ & $\begin{array}{c}\text { Non-PLTW } \\
\text { School Students }\end{array}$ \\
\hline Percent non-white & $18.5 \%$ & $14.6 \%$ & $13.7 \%$ \\
Percent Eligible for Free and & $29.4 \%$ & $26.5 \%$ & $20.8 \%$ \\
Reduced Lunch & & & \\
Percent Male & $48.5 \%$ & $45.2 \%$ & $46.5 \%$ \\
Percent Honors Diploma & $29.6 \%$ & $29.7 \%$ & $34.8 \%$ \\
Average ISTEP+ Math Score & 570.64 & 574.32 & 600.38 \\
& $\mathrm{SD}=71.412$ & $\mathrm{SD}=68.215$ & $\mathrm{SD}=6.234$ \\
Average ISTEP+ ELA Score & 549.14 & 552.83 & 559.44 \\
& $\mathrm{SD}=49.304$ & $\mathrm{SD}=48.970$ & $\mathrm{SD}=43.027$ \\
\hline
\end{tabular}

The finding from these three models was a statistically significant difference on majoring in STEM between PLTW students and their non-PLTW peers at the same schools $(\mathrm{p}<.001, \mathrm{OR}=2.74)$ and PLTW students and students at non-PLTW schools $(\mathrm{p}<.001, \mathrm{OR}=3.30)$. There was no statistical difference between nonPLTW students at PLTW schools and students at non-PLTW schools $(\mathrm{p}=.852)$.

Hypothesis 2

$\mathbf{H}_{\mathbf{a}}$ : Attending a school that offers PLTW will increase the likelihood that a student will persist from his/her freshman to sophomore year of college.

$\mathbf{H}_{\mathbf{0}}$ : Attending a school that offers PLTW will not increase the likelihood that a student will persist from his/her freshman to sophomore year of college.

Attending a school that offers PLTW was not a significant predictor for persisting from freshman to sophomore year of college. Therefore the null hypothesis cannot be rejected. For this analysis the dependent variable was if a student persisted from his/her freshman to sophomore years of college. This was a dichotomous variable that was coded as 0 (anyone who did not continue after their freshman year) and 1 (anyone who completed the first semester of their sophomore year). Three levels of data were used, where level 1 was student level data $(\mathrm{N}=28956)$, level 2 was school data $(\mathrm{N}=348)$, and level 3 data was district/community level data $(\mathrm{N}=289)$. Table 4.11 provides basic information about the PLTW schools and the non-PLTW schools. 
Table 3: Basic descriptive statistics of PLTW schools and non-PLTW schools

\begin{tabular}{lcc}
\hline \multicolumn{1}{c}{ Descriptive } & PLTW Schools & Non-PLTW Schools \\
\hline Number of Schools & 233 & 115 \\
$\begin{array}{l}\text { Percentage of Schools that are } \\
\text { rural }\end{array}$ & 42.9 & 43.5 \\
Maximum Enrollment & 3632 & 4389 \\
Minimum Enrollment & 171 & 53 \\
Average Enrollment & 1035 & 758 \\
Number of Students in Analysis & 21844 & 7112 \\
\hline
\end{tabular}

An initial unconditional analysis was run to determine if a three level model was appropriate. The $\mathrm{p}$-value for this unconditional model was $\mathrm{p}<.001$ indicating that the three level model was appropriate (Hox, Moerbeek, \& Van de Schoot, 2017). A model was then run including the dichotomous variable providing if a school had PTLW (1) or not (0). The equation of this model is $\eta_{i j k}=\gamma_{000}+$ $r_{010}{ }^{*}$ ISPLTWSC $j k+r_{0 j k}+u_{00 k}$. Based upon the outcomes of this model, it was found that students attending a PTLW school were not more likely to persist from their freshman to sophomore years of post-secondary education $(p=.438)$.

\section{Data Analysis and Interpretation}

Descriptive statistics were used to describe the PLTW schools and non-PLTW schools, their communities, and the six groups of students. This descriptive analysis provides details of the general configurations of the communities, schools, and students. The data that were used to answer the research questions are contained at three levels (district/community, school, student), with each level of data nested within the level above it. To analyze these types of data a multi-level analysis using Hierarchical Linear Modeling was conducted. Multilevel nested data structures have been analyzed in many areas of research. A few examples include business research (Peterson, Arregle, \& Martin, 2012; Yang, \& Schwarz, 2016), medical research (Friedmann et al., 2013; Gagnon et al., 2016; Van Hecke et al., 2016) and educational research (Dettmers, Trautwein, Ludtke, Kunter, \& Baumert, 2010; Nagengast \& Marsh, 2012).

Analysis of these multilevel data structures containing data that are nested within levels can create statistical problems with the heterogeneity of regression slopes, the estimation of standards errors, and issues with aggregation bias. Aggregation bias arises by making the assumption that what is true about the group is true about the individual and can occur when a variable takes on different meanings at different levels of the model. Estimation of standard errors issues can occur when student level data are treated as independent even though factors from the levels in which they are nested impact them. Similarly, issues with similar regression slopes within nested data can also occur because of the similarity of the nested situations. In other words, student achievement based on race or socioeconomic status may vary depending upon the school and district the student attends. (Lee, 2000; Woltman, Feldstain, MacKay, \& Rocchi, 2012).

Many techniques and applications have been developed to combat these potential issues when working with nested data (King, Hernandez, \& Lott, 2012; 
Steenbergen \& Jones, 2002). This study avoided these nesting issues by utilizing Hierarchical Linear Modeling. HLM uses multi-level linear regression that allows for the analysis of effects from both within and between levels using a nested design and eliminates the aforementioned statistical difficulties. Figure 1.2 provides a diagram of the levels and variables that will be used within the models. Nesting of students within schools and schools within districts to measure the impact of different levels of factors is an appropriate use of HLM.

\section{Conclusions and Discussion}

Hypothesis 1

$\mathbf{H}_{\mathbf{a}}$ : Attending a school that offers PLTW will increase the likelihood of students majoring in a post-secondary STEM program. This odds ratio will be greater if they have taken PLTW courses.

$\mathbf{H}_{\mathbf{0}}$ : Attending a school that offers PLTW will not increase the likelihood of students majoring in a post-secondary STEM program. This odds ratio will be greater if they have taken PLTW courses.

When controlling for students who took a PLTW course, attending a school that offers PLTW did not increase the likelihood of students majoring in STEM. We therefore cannot reject the null hypothesis. For this analysis, the dependent variable was if a student majored in STEM. This was a dichotomous variable coded as 0 (anyone who did not have a major in a STEM field during their first semester of higher education) and 1 (their major the first semester of higher education was in a STEM field). Three levels of data were used, where level 1 were student level data $(\mathrm{N}=55612)$, level 2 were school data $(\mathrm{N}=346)$, and level 3 were district/community level data $(\mathrm{N}=289)$. Table 4.9 provides basic information about the PLTW schools and the non-PLTW schools.

Table 4: Basic descriptive statistics of PLTW schools and non-PLTW schools

\begin{tabular}{lcc}
\hline \multicolumn{1}{c}{ Descriptive } & PLTW Schools & Non-PLTW Schools \\
\hline Number of Schools & 233 & 115 \\
Percentage of Schools that are & 42.9 & 43.5 \\
rural & 3632 & 4389 \\
Maximum Enrollment & 171 & 53 \\
Minimum Enrollment & 1035 & 758 \\
Average Enrollment & & \\
\hline
\end{tabular}

An initial unconditional analysis was run to determine if a three level model was appropriate. Because of the dichotomous outcome variable, use of a Bernoulli HLM3 analysis is appropriate for all analyses using the variable of STEM Major as the outcome variable (Raudenbush et al., 2011). The p-value for this unconditional model was $\mathrm{p}<.001$ indicating that the three level model was appropriate (Hox, Moerbeek, \& Van de Schoot, 2017). A model was then run including the dichotomous variable PLTWSCHL [school offers PTLW (1) or a school does not offer PLTW (0)]. The equation of this model is $\eta_{i j k}=\gamma_{000}+$ $r_{010}{ }^{*}$ ISPLTWSC $_{j k}+r_{0 j k}+u_{00 k}$. The results of this model showed that students attending a PTLW school were more likely to major in STEM than students at a non PLTW School $(\mathrm{p}<.001, \mathrm{OR}=1.28)$. Further investigation was done to 
determine if PLTW students solely accounted for this difference. To determine this, another model was run to include and control for PLTW students. The results of this model, $\eta_{i j k}=\gamma_{000}+\gamma_{010}{ }^{*}$ ISPLTWSC $_{j k}+\gamma_{100}{ }^{*}$ ISPLTW $_{i j k}+r_{0 j k}+u_{00 k}$, were that PLTW students were more likely to major in STEM than non-PLTW students $(\mathrm{p}<.001, \mathrm{OR}=4.66)$ and attending a PLTW school was not significant $(\mathrm{p}=.672)$.

New models were created to further investigate the differences in majoring in STEM. Models were setup to compare PLTW students $(\mathrm{N}=4032)$ to non-PLTW students $(\mathrm{N}=37774)$ at their school, PLTW students to students at non-PLTW schools $(\mathrm{N}=13806)$ and non-PLTW students at PLTW schools to students at nonPLTW schools. Table 4.10 shows basic information about each of these groups of students.

Table 5: Basic descriptive statistics of student groups

\begin{tabular}{lccc}
\hline \multicolumn{1}{c}{ Descriptive } & PLTW Students & $\begin{array}{c}\text { Non-PLTW Students } \\
\text { at PLTW Schools }\end{array}$ & $\begin{array}{c}\text { Non-PLTW } \\
\text { School Students }\end{array}$ \\
\hline Percent non-white & $18.5 \%$ & $14.6 \%$ & $13.7 \%$ \\
Percent Eligible for Free and & $29.4 \%$ & $26.5 \%$ & $20.8 \%$ \\
Reduced Lunch & $48.5 \%$ & $45.2 \%$ & $46.5 \%$ \\
Percent Male & $29.6 \%$ & $29.7 \%$ & $34.8 \%$ \\
Percent Honors Diploma & 570.64 & 574.32 & 600.38 \\
Average ISTEP+ Math Score & $\mathrm{SD}=71.412$ & $\mathrm{SD}=68.215$ & $\mathrm{SD}=6.234$ \\
& 549.14 & 552.83 & 559.44 \\
Average ISTEP+ ELA Score & $\mathrm{SD}=49.304$ & $\mathrm{SD}=48.970$ & $\mathrm{SD}=43.027$ \\
\hline
\end{tabular}

The finding from these three models was a statistically significant difference on majoring in STEM between PLTW students and their non-PLTW peers at the same schools $(\mathrm{p}<.001, \mathrm{OR}=2.74)$ and PLTW students and students at non-PLTW schools $(\mathrm{p}<.001, \mathrm{OR}=3.30)$. There was no statistical difference between nonPLTW students at PLTW schools and students at non-PLTW schools $(\mathrm{p}=.852)$.

Hypothesis 2

$\mathbf{H}_{\mathbf{a}}$ : Attending a school that offers PLTW will increase the likelihood that a student will persist from his/her freshman to sophomore year of college.

$\mathbf{H}_{\mathbf{o}}$ : Attending a school that offers PLTW will not increase the likelihood that a student will persist from his/her freshman to sophomore year of college.

Attending a school that offers PLTW was not a significant predictor for persisting from freshman to sophomore year of college. Therefore the null hypothesis cannot be rejected. For this analysis the dependent variable was if a student persisted from his/her freshman to sophomore years of college. This was a dichotomous variable that was coded as 0 (anyone who did not continue after their freshman year) and 1 (anyone who completed the first semester of their sophomore year). Three levels of data were used, where level 1 was student level data $(\mathrm{N}=28956)$, level 2 was school data $(\mathrm{N}=348)$, and level 3 data was district/community level data $(\mathrm{N}=289)$. Table 4.11 provides basic information about the PLTW schools and the non-PLTW schools. 
Table 6: Basic descriptive statistics of PLTW schools and non-PLTW schools

\begin{tabular}{lcc}
\hline \multicolumn{1}{c}{ Descriptive } & PLTW Schools & Non-PLTW Schools \\
\hline Number of Schools & 233 & 115 \\
$\begin{array}{l}\text { Percentage of Schools that are } \\
\text { rural }\end{array}$ & 42.9 & 43.5 \\
Maximum Enrollment & 3632 & 4389 \\
Minimum Enrollment & 171 & 53 \\
Average Enrollment & 1035 & 758 \\
Number of Students in Analysis & 21844 & 7112 \\
\hline
\end{tabular}

An initial unconditional analysis was run to determine if a three level model was appropriate. The $\mathrm{p}$-value for this unconditional model was $\mathrm{p}<.001$ indicating that the three level model was appropriate (Hox, Moerbeek, \& Van de Schoot, 2017). A model was then run including the dichotomous variable providing if a school had PTLW (1) or not (0). The equation of this model is $\eta_{i j k}=\gamma_{000}+$ $r_{010}{ }^{*}$ ISPLTWSC $j k+r_{0 j k}+u_{00 k}$. Based upon the outcomes of this model, it was found that students attending a PTLW school were not more likely to persist from their freshman to sophomore years of post-secondary education $(p=.438)$.

Attributes of the community can have a significant impact on the outcomes from an action situation. This is certainly true in the role that the attributes of the community play in students across Indiana majoring in STEM. The percent of the population with a high school diploma and above or bachelor's degree and above (education level of a community) are each significant predictors in both the adoption of PLTW by a school and the future probability of the students majoring in STEM. While community level factors impact all students majoring in STEM, they appear to have a greater effect on PLTW students. This might be because PLTW experiences provide students with a better vision of being a STEM major, and the PLTW students who come from a family with greater educational attainment may feel better supported in pursuing a STEM degree.

PLTW students also have different factors that impact the likelihood they will major in STEM when compared to non-PLTW students. For example, being female is not a negative predictor of majoring in STEM for PLTW students. Also non-white students in PLTW are more likely to major in STEM than white PLTW students. These students' PLTW experiences may empower them by providing them with the confidence and experience to believe they can succeed in STEM majors predominantly associated with white and Asian males.

When looking at whether PLTW influences students in selecting a STEM major, the data were not initially transparent. Students who attended a PLTW school were significantly more likely to major in STEM than students at a non-PLTW school (odds ratio=1.28) until controlling for whether a student was in PLTW. When the model controlled for PLTW students, attending a PLTW school was no longer statistically significant. Instead being a PLTW student $(\mathrm{p}<.001$, odds ratio=4.66) was significant. When comparing PLTW students, non-PLTW students at PLTW schools, and students at non-PLTW schools, there was no statistical difference between the two non-PLTW groups. This suggests the influence of PLTW on the non-PLTW students at the school is minimal. 
Further, PLTW students were more likely to major in STEM compared to either of the non-PLTW student groups. This finding is supported by other research done on these same data (Pike \& Robbins, 2014) using a direct comparison to a like group of students selected through propensity score matching. PLTW students make up less than $10 \%$ of their school population, but enough of them majored in STEM to make the overall STEM major percentages for the entire school different from that of the students at the non-PLTW schools. While PLTW first appears to impact the likelihood of all PLTW school students majoring in STEM, in actuality it did not. As a result of this, school administrators should encourage current PLTW teachers who also teach non-PLTW courses to model these non-PLTW courses after their PLTW course. Administrators should also consider helping other STEM subject area teachers implement more student centered, project-based or inquiry learning modeled after successful PLTW teachers in their school. Additionally, PLTW could evaluate ways to support teachers implementing their materials in implementing similar instructional strategies in other courses.

When looking at the factors that impact a student majoring in STEM, it becomes apparent that PLTW does influence its own students but does not influence the student body as a whole. Variables predicting majoring in STEM for students at PLTW schools and non-PLTW schools are almost identical, with variation in only one variable. In two of the three models, free and reduced lunch is a negative predictor for majoring in STEM for PLTW school students but not for non-PLTW school students. This may be because non-PLTW schools $(20.8 \%)$ have a lower percentage of free and reduced lunch eligible students than PLTW schools $(26.5 \%)$. These PLTW students who are eligible for free and reduced lunch may be directly entering the STEM workforce after high school. PLTW school administrators and teachers should be aware of the pathways these students are taking and make sure, if they are interested in post-secondary education that they are aware of the many different ways to fund this education.

However, there are several significant differences when comparing the STEM predictor variables of the two school groups with PLTW students. Gender (being male) was a significant predictor for majoring in STEM for PLTW schools $(p<.001)$ and non-PLTW schools $(p<.001)$ but not for PLTW students. Females who took PLTW courses are statistically as likely to major in STEM as boys in PLTW. The same cannot be said for non-PLTW students. This suggests that PLTW courses attract and/or encourage both females and non-white students to major in STEM.

Regarding free and reduced lunch eligibility, PLTW students align similarly to their school peers in that being eligible for the free and reduced lunch program decreases the likelihood of majoring in STEM (OR=.79). ISTEP+ ELA score is a negative predictor of majoring in STEM for students at PLTW schools and nonPLTW schools but is not a predictor for PLTW students. These findings imply that taking PLTW has a significant impact on the probability of multiple underrepresented populations (females and non-whites) majoring in STEM but not for the PLTW school as a whole. Therefore, leadership and teachers at PLTW schools should continue to actively recruit underrepresented students with an interest in STEM education into PLTW courses or other STEM courses that will 
promote their interest in majoring in STEM and provide them with real life hands on learning opportunities.

Socio-economic factors play a significant role in predicting if a PLTW student, and all Indiana students, will major in STEM. However, education level factors (percent of population with a high school diploma/Bachelor's and above) for PLTW had a much smaller predicted odds ratio than for the two non-PLTW groups. This suggests that PLTW may help overcome some community level factors related to education that affect a student decision to major in STEM. When controlling for level 1 and 2 variables community education levels and per capita income have the largest odds ratios of all factors for each of the three student groups. However, the odds ratios of these factors are proportionally larger for PLTW students than for the two non-PLTW student groups. It is not advisable to make a direct comparison between the odds ratios of different multi-level models. However, in these models there are large differences in the odds ratio and the confidence intervals between the models for students who took PLTW courses, students at schools who offer PLTW but did not take a PLTW course, and students attending a school that did not offer PLTW for the percent of the population with a high school degree and above and the percent of the population with a bachelor degree and above. These findings suggest that these two variables have a larger effect on PLTW students than non-PLTW students. Teachers, administrators, policymakers, and PLTW should take this finding into careful consideration as helping students who may come from a less educated background or live in a less educated area may need greater support structures to help them pursue post-secondary education. It is possible that these students have opted to go directly into the workforce, in which case school leadership should make sure these students have been given a clear understanding of pathways they can take into post-secondary education should they so choose later in their life or while they are working.

\section{Conclusion}

These results imply that PLTW had a statistically significant impact on the students participating in the program excluding students who were eligible for free and reduced lunch. However, this impact does not appear to carry over to the rest of the student body that does not participate in PLTW. One assumes the impact from PLTW occurs because of the PLTW curriculum and/or instructional practices. If this is the case, it appears that neither the curriculum nor instructional practices are positively impacting the instruction of other teachers in the school. Potentially, this impact is not even reaching into non-PLTW courses being taught by the PLTW teachers. As stated earlier, this is important for not only school leaders but PLTW as well. Careful reflection should be given as to why many PLTW teachers are potentially not creating the same learning environments in non-PLTW courses they are teaching. While they may see the effectiveness of this teaching style in their PLTW course(s) why are they not carrying this to their other courses?

Attributes of the community have a significant impact on schools adopting PLTW and the likelihood of students majoring in STEM. This is not surprising. Schools whose students are performing better academically are better positioned to adopt and implement new programs. This, then, could also explain why 
schools with a lower percentage of non-white students are more likely to adopt PLTW as this variable is strongly correlated with graduation rates. Additionally, the data suggest that PLTW may have a positive impact on some underrepresented populations such as females and non-white students but a negative impact on students who are eligible for the free and reduced lunch program. Sadly, schools with a larger population of non-white students are less likely to adopt PLTW, suggesting that there is still a significant gap in providing this program to a student population that it may benefit. PLTW was utilized in this research for several reasons. Teachers across the state and country utilize the same curriculum when teaching the same course. Additionally, each of these teachers will have, at a minimum, attended the two week PLTW training before they receive the curriculum. While implementation of any curriculum will never be identical, these factors should allow for a much more consistent implementation of the PLTW courses than a program without training and consistent curriculum. When thinking about the findings of this research, it is important to think of them beyond one STEM program. When looking at the findings for the district and community level factors we see that they play a significant role in a student's decision to major in STEM as well as persisting in STEM. Given any STEM program the policies and support structure put in place must reflect these factors.

\section{References}

Bottoms, G., \& Anthony, K. (2005). Project Lead the Way: A Pre-engineering Curriculum That Works A New Design for High School Career/Technical Studies. https://www.pltw.org/bulletins/SREB_Research_Brief.pdf.

Chen, Y., Johri, A., \& Rangwala, H. (2018, March). Running out of stem: a comparative study across stem majors of college students at-risk of dropping out early. In Proceedings of the 8th International Conference on Learning Analytics and Knowledge (pp. 270-279). ACM. https://doi.org/10.1145/3170358.3170410

Dettmers, S., Trautwein, U., Ludtke, O., Kunter, M., \& Baumert, J. (2010). Homework works if homework quality is high: Using multilevel modeling to predict the development of achievement in mathematics. Journal of Educational Psychology, 102(2), 467. http://dx.doi.org/10.1037/a0018453

Friedmann, P. D., Ducharme, L. J., Welsh, W., Frisman, L., Knight, K., Kinlock, T., . . . Pankow, J. (2013). A Cluster randomized trial of an organizational linkage intervention for offenders with substance use disorders: study protocol. Health $\mathcal{E}$ Justice, 1(1), 6. https:/ / doi.org/10.1186/2194-7899-1-6

Gagnon, M. P., Simonyan, D., Ghandour, E. K., Godin, G., Labrecque, M., Ouimet, M., \& Rousseau, M. (2016). Factors influencing electronic health record adoption by physicians: A multilevel analysis. International Journal of Information Management, 36(3), 258-270. https:/ / doi.org/10.1016/j.ijinfomgt.2015.12.002

Hoeg, D. G., \& Bencze, J. L. (2017). Values underpinning STEM education in USA: An analysis of the Next Generation Science Standards. Science Education, 101(92), 278-301. https://doi.org/10.1002/sce.21260

Hox, J. J., Moerbeek, M., \& Van de Schoot, R. (2017). Multilevel analysis: Techniques and applications. Routledge. https://doi.org/10.4324/9781315650982

King, J. P., Hernandez, J. M., \& Lott, J. L. (2012). Using Existing Data Sources/Programs and Multilevel Modeling Techniques for Questions in Institutional Research. New Directions for Instiutional Research 2012, 154, 41-55. https://doi.org/10.1002/ir.20013 
Laanan, F. S., Schenk, T., Starobin, S., Chapman, M., \& Zhang, L. Y. (2009). Project Lead the Way in Iowa: a longitudinal evaluation: Iowa State University, University of Iowa, Iowa Department of Education.

Lee, V. E. (2000). Using Hierarchical Linear Modeling to Study Social Contexts: The Case of School Effects. Educational Psychologist, 35(2), 125-141. https://doi.org/10.1207/s15326985ep3502_6

McREL. (2010). Changing the Odds: What Matters Most for Student Achievement. McREL. Denver, CO. Retrieved from http:/ / www.mcrel.org/ changing-theodds-what-matters-most-for-student-achievement-2010

Moore, T. J., \& Smith, K. A. (2014). Advancing the state of the art of STEM integration. Journal of STEM Education: Innovations and Research, 15(1), 5-10.

National Academy of Science, C. o. S., Engineering and Public Policy (COSEPUP). (2006). Rising Above the Gathering Storm: Energizing and Employing America for a Brighter Economic Future. Washington, D.C.: National Academies Press.

Nagengast, B., \& Marsh, H. (2012). Big fish in little ponds aspire more: Mediation and cross-cultural generalizability of school-average ability effects on self-concept and career aspirations in science. Journal of Educational Psychology, 104(4). https://doi.org/10.1037/a0027697

Peterson, M. F., Arregle, J.-L., \& Martin, X. (2012). Multilevel models in international business research. J Int Bus Stud, 43(5), 451-457. https:/ / doi.org/10.1007/978-3030-22113-3_23

Pike, G. R., \& Robbins, K. (2014, March). Using propensity scores to evaluate education programs. In annual meeting of the Indiana Association for Institutional Research, Indianapolis, IN.

Project Lead The Way. (2019). Retrieved from https://www.pltw.org/

Ring, E. A., Dare, E. A., Crotty, E. A., \& Roehrig, G. H. (2017). The evolution of teacher conceptions of STEM education throughout an intensive professional development experience. Journal of Science Teacher Education, 28(5), 444-467. https://doi.org/10.1080/1046560x.2017.1356671

Schenk, T., Retwisch, D., Laanan, F. S., Starobin, S., Zhang, Y., \& Chapman, M. (2009). Project Lead The Way: Interim Research Report: Iowa Department of Education.

Steenbergen, M. R., \& Jones, B. S. (2002). Modeling Multilevel Data Structures. American Journal of Political Science, 46(1), 218-237. https:// doi.org/10.2307/3088424

Thibaut, L., Knipprath, H., Dehaene, W., \& Depaepe, F. (2018). The influence of teachers' attitudes and school context on instructional practices in integrated STEM education. Teaching and Teacher Education, 71, 190-205. https://doi.org/10.1016/j.tate.2017.12.014

U.S. Congress Joint Economic Committee. (2012). STEM Education: Preparing for the Jobs of the Future. Washington, DC: U.S. Congress Retrieved from http://www.jec.senate.gov/public/index.cfm?a=Files.Serve\&File_id=6aaa7e1f9586-47be-82e7-326f47658320.

Van Hecke, A., Van Lancker, A., De Clercq, B., De Meyere, C., Dequeker, S., \& Devulder, J. (2016). Pain intensity in hospitalized adults: a multilevel analysis of barriers and facilitators of pain management. Nursing research, 65(4), 290-300. https://doi.org/10.1097/nnr.0000000000000160

Van Overschelde, J. P. (2013). Project Lead The Way students more prepared for higher education. American Journal of Engineering Education (AJEE), 4(1), 1-12. https:// doi.org/10.19030/ajee.v4i1.7854

Wang, H. H., Moore, T. J., Roehrig, G. H., \& Park, M. S. (2011). STEM integration: Teacher perceptions and practice. Journal of Pre-College Engineering Education Research, 1(2), 1-13. 
Woltman, H., Feldstain, A., MacKay, J. C., \& Rocchi, M. (2012). An Introduction to hierarchical linear modeling. Tutorials in Quantitative Methods for Psychology, 8(1), 52-69. https://doi.org/10.20982/tqmp.08.1.p052

Yang, K. P., \& Schwarz, G. M. (2016). A multilevel analysis of the performance implications of excess control in business groups. Organization Science, 27(5), 1219-1236. https://doi.org/10.1287/orsc.2016.1086 